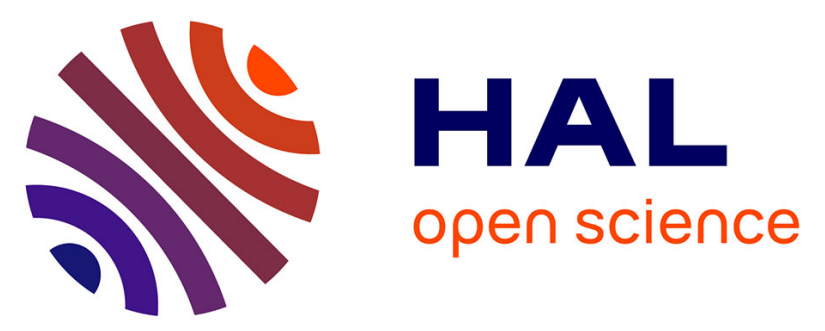

\title{
Antioxidant Potential is Correlated to $\omega 6$ / $\omega 3$ Ratio and Brasfield Score in Cystic Fibrosis Children
}

Alexandre Fabre, Sylvie Caspar-Bauguil, Jean Gaudart, Julien Mancini, Jésus Garcia, Marie Mittaine, Jean-Luc Rittié, François Brémont, Emmanuel Mas

\section{To cite this version:}

Alexandre Fabre, Sylvie Caspar-Bauguil, Jean Gaudart, Julien Mancini, Jésus Garcia, et al.. Antioxidant Potential is Correlated to $\omega 6$ / $\omega 3$ Ratio and Brasfield Score in Cystic Fibrosis Children. International Journal for Vitamin and Nutrition Research, 2013, 10.1024/0300-9831/a000174 . hal01307572

\section{HAL Id: hal-01307572}

https://hal-amu.archives-ouvertes.fr/hal-01307572

Submitted on 28 Apr 2016

HAL is a multi-disciplinary open access archive for the deposit and dissemination of scientific research documents, whether they are published or not. The documents may come from teaching and research institutions in France or abroad, or from public or private research centers.
L'archive ouverte pluridisciplinaire HAL, est destinée au dépôt et à la diffusion de documents scientifiques de niveau recherche, publiés ou non, émanant des établissements d'enseignement et de recherche français ou étrangers, des laboratoires publics ou privés.

\section{(ㅇ)(1) $\$$}

Distributed under a Creative Commons Attribution - NonCommercial - NoDerivatives 44.0 


\section{Pre-Print}

\section{ANTIOXIDANT POTENTIAL IS CORRELATED TO $\omega 6 / \omega 3$ RATIO}

\section{AND BRASFIELD SCORE IN CYSTIC FIBROSIS CHILDREN}

Alexandre Fabre $\mathrm{MD}, \mathrm{PhD}^{1}$, Sylvie Caspar-Bauguil $\mathrm{PhD}^{2}$, Jean Gaudart $\mathrm{MD}^{3}$, Julien Mancini MD³ , Jésus Garcia², Marie Mittaine MD $^{4}$, Jean-Luc Rittié MD François Brémont $\mathrm{MD}^{4}$, Emmanuel Mas $\mathrm{MD}, \mathrm{PhD}^{5,6,7,8}$

${ }^{1}$ Service de pédiatrie multidisciplinaire, Hôpital des Enfants de la Timone, 264 rue Saint Pierre - 13005 Marseille

${ }^{2}$ Laboratoire de Biochimie nutritionnelle, Institut Fédératif de Biologie, Hôpital Purpan, 330 avenue de Grande-Bretgne - TSA 40031 - 31059 Toulouse cedex

9, France

${ }^{3}$ APHM, CHU Timone, Service de santé publique et d'information médicale, Marseille, F-13005, France ; UMR912, SESSTIM, Université Aix-Marseille, Inserm, IRD, F-13005 Marseille, France

${ }^{4}$ Service de pneumologie, Hôpital des Enfants, CHU Toulouse, Toulouse, F31300, France

${ }^{5}$ Unité de Gastroentérologie, Hépatologie, Nutrition et Diabétologie, Hôpital des Enfants, CHU Toulouse, Toulouse, F-31300, France

${ }^{6}$ INSERM U1043, Toulouse, F-31300, France

${ }^{7}$ CNRS, U5282, Toulouse, F-31300, France

${ }^{8}$ Université de Toulouse, UPS, Centre de Physiopathologie de Toulouse Purpan (CPTP), Toulouse, F-31300, France

Running title: Oxidative stress (KRL test) in CF 
Keywords: oxidative stress, fatty acids, nutritional status, respiratory system, children

\section{ABSTRACT}

Objectives: Oxidative stress is involved in cystic fibrosis (CF), but no guidelines for its assessment or its treatment exist. Our aim was to evaluate a test that measures the whole antioxidant capability in CF children.

Methods: The whole blood antioxidant capability was assessed by the KRL test in $44 \mathrm{CF}$ children (24 boys). We recorded several data on the same day: anthropometric measures, pulmonary function, $\mathrm{CF}$ severity scores, and plasma nutritional and inflammatory parameters (proteins, vitamins, erythrocyte fatty acids, micronutrients). We performed univariate and multivariate analyses with linear regression models.

Results: The mean age at the first KRL assessment was $12.2 \pm 3.8$ years. The factors correlated to a diminution of the antioxidant capacity were mostly related to the severity of pulmonary disease (FEV1, acute exacerbation, and congestion). In multivariate analysis, the correlation between Brasfield score and erythrocyte antioxidant potential remained significant $(\beta=-0.611, \mathrm{p}<0.001)$. Among nutritional factors, $\omega 6 / \omega 3$ ratio was significantly correlated to erythrocyte antioxidant potential $(\beta=-1.213, \mathrm{p}=0.01)$.

Conclusion: The whole antioxidant capability, measured by the KRL test, should be a useful biomarker to assess oxidative stress in CF patients. This study suggests that $\omega 6 / \omega 3$ ratio should be relevant nutritional end-point in the management of antioxidant potential in CF children. 


\section{Introduction}

It was already demonstrated that oxidative stress was involved in the pathophysiology of cystic fibrosis (CF), while recurrent pulmonary infections, chronic pulmonary inflammation and abnormal lung epithelium homeostasis increase the release of oxidative molecules, and antioxidants like micronutrients and fat-soluble vitamins are decreased [1-4]. However, no guidelines are established for the follow-up of oxidative stress or antioxidant potential in clinical practice in CF.

Oxidative stress is defined as an abnormal oxidant/antioxidant balance, secondary to either an increase of oxidants or a decrease of antioxidants [1]. In $\mathrm{CF}$, large amounts of reactive oxygen species (ROS) are released by neutrophils that are present in bronchial lumen [1]. Other sources of ROS come from bronchial cilated and alveolar type II epithelial cells, and Pseudomonas aeruginosa [1]. These ROS alter bacteria phagocytosis. ROS are second messengers that can activate, through $\mathrm{NF}-\mathrm{\kappa B}$ pathway, the transcription of inflammatory cytokines, mainly IL-6 and IL-8 [1]. Oxidants can also increase lipid peroxidation, producing several pro-inflammatory lipid mediators. Oxysterols, which are produced by oxidation of cholesterol, are increased in CF [7]. The oxidation of arachidonic acid (AA) produces acid 8-isoprostane prostaglandin F2 $\alpha$ [8]. Plasma level of this eicosanoid is increased after pulmonary exacerbations [8]. The imbalance is also due to a decreased level of glutathione (GSH), an impaired NO metabolism, and an abnormal intracellular $\mathrm{H}_{2} \mathrm{O}_{2}$ production [1]. Antioxidants present at respiratory surface are ascorbate, urate, $\alpha$-tocopherol, GSH, and mucins [6]. GSH is the only antioxidant present in larger amount in epithelial lining fluid than in plasma; however GSH levels 
are decreased to $5-10 \%$ in epithelial lining fluid and to $50 \%$ in plasma of CF patients [6].

Nutritional status is important in CF management. It is associated with both pulmonary status and survival [9]. In the setting of oxidative stress, protein malnutrition contributes to decreased albumin level and secondarily to low GSH levels [6]. Albumin can not provide all cysteine required for GSH production [6]. Pancreatic insufficiency causes malabsorption of fat-soluble antioxidants such as carotenoids, vitamin E, and coenzyme Q-10 [1, 6]. There is also an abnormal fatty acid pattern in CF that is characterized by a decrease in the plasma levels of linoleic acid and docosahexaenoic acid (DHA) and an increase in the levels of AA and eicosapentaenoic acid [10, 11]. These abnormalities are present even in well-nourished children, suggesting an involvement of the protein CFTR in fatty acid metabolism rather than fat malabsorption [11]. AA promotes the production of inflammatory mediators while $\omega 3$ polyunsaturated fatty acids (PUFA), DHA and eicosapentaenoic acid (EPA), are involved in the resolution of inflammation [1, 12]. Around $90 \%$ of CF patients require pancreatic enzyme replacement therapy (PERT) and fatsoluble vitamin supplementation. However, the amount of antioxidant vitamin supplementation could be different to obtain normal plasma vitamin levels or to correct oxidant/antioxidant balance $[5,6]$. For example, CF Foundation recommends 40-400 IU/d of vitamin E to normalize plasma levels [13]. To reach an antioxidant effect, $1600 \mathrm{IU} / \mathrm{d}$ of vitamin $\mathrm{E}$ were required in hypercholesterolemic subjects [1]. However, some studies reported that highdosage vitamin E supplementation increased risk of heart failure, coagulopathy, and death $[6,14]$. Carotenoid supplementation had also positive results on 
oxidative stress in CF trials. Vitamin $\mathrm{E}$ and carotenoid induced a decrease of markers of lipid peroxidation, like 8-isoprostane prostaglandin $F_{2} \alpha$ and malondialdehyde respectively [6]. However, the clinical relevance of these improvements is unknown. Of note, large cancer prevention trials that used $\alpha$ tocopherol and $\beta$-carotene (ATBC trial) or $\beta$-carotene and retinyl palmitate (CARET trial) lead to an excess lung cancer incidence and an excess mortality in the active vitamin treatment arm [15]. The cardiovascular mortality was also increased. Finally, micronutrient deficiencies, mainly selenium and zinc, which are frequent in $\mathrm{CF}$, can alter the function of enzymatic antioxidants [1, 6]. Zinc is a cofactor of superoxide dismutase and selenium is en essential component of GSH peroxidase and thioredoxin reductases [6].

Oxidative stress can be assessed by several biomarkers $[1,5,6]$. The aim of this study was to use a test that measured the whole antioxidant capability in CF children, using a rapid and standardized test (KRL test). We also looked for a correlation with appropriate clinical, biochemical, and radiological parameters. 


\section{Subjects and methods}

\subsection{Subjects}

Between 09/11/2006 and 09/03/2008, oxidative stress was measured on blood samples in our pediatric CF unit. We retrospectively analysed blood samples of $44 \mathrm{CF}$ children collected during this period. Children were assessed once $(n=19)$, twice $(n=22)$ or three times $(n=3)$, resulting in a total of 72 samples. During this out-clinic visit, anthropometric parameters (weight, height, body mass index (BMI) z-score, height to weight (H/W) ratio) and respiratory status (congestion, exacerbation, forced expiratory volume in 1 second (FEV1) (\%) and maximum midexpiratory flow (MMEF) [16]) were noted in a computerized database. Their treatments, like fat-soluble vitamins, PERT, selenium supplementation, and ursodeoxycholic acid, were registered. A single physician (FB) also retrospectively evaluated CF severity scores (Shwachman and Brasfield scores). Shwachman score is composed of 4 items (general activity, physical examination, nutrition status, and radiological findings). The note of each item is $5,10,15,20$, or 25 , ranging from severe to excellent. Thus, Shwachman score can be excellent (86-100), good (71-85), average (56-70), poor (41-55), or severe $(\leq 40)$. Brasfield radiological score describes several items (air trapping, linear markings, nodular cystic lesions, large lesions, and general severity. This score varies from 0 to 25 (normal to severe).

We recorded the anthropometric parameters and FEV1 values obtained 6 months before to look for patient evolution prior to oxidative stress analysis. We calculated the evolution of BMI z-score and FEV1 during this period, respectively (z-BMI - z-BMI $\left.{ }^{\mathrm{M}-6}\right) / \mathrm{z}-\mathrm{BMI}{ }^{\mathrm{M}-6}$ and (FEV1 - FEV1 $\left.{ }^{\mathrm{M}-6}\right) / \mathrm{FEV} 1^{\mathrm{M}-6}$, respectively defined as BMIev and FEV1ev. 


\subsection{Biological parameters}

A blood sample was usually drawn for biological analyses. For this study, we collected the values of liver function tests (aspartate aminotransferase (AST), alanine amino-transferase (ALT), gamma-glutamyl transpeptidase (GGT)), blood cell count, creatinin level, nutritional and inflammatory proteins (prealbumin, albumin, retinol binding protein, ceruloplasmin, transferin, orosomucoid, and $\mathrm{C}$ reactive protein), micronutrients (zinc, cupper, and selenium), fat-soluble vitamins (retinol, and $\alpha$-tocopherol), and lipids levels (total cholesterol, triglycerides, and erythrocyte fatty acids).

Erythrocyte fatty acid composition was determined by capillary gas chromatography. Red blood cells were separated from plasma by centrifugation at $1730 \mathrm{~g}$ for 10 minutes at $4{ }^{\circ} \mathrm{C}$ and washed three times with an equal volume of cold physiological $(9 \mathrm{~g} / \mathrm{L} \mathrm{NaCl})$ solution. Lipid extraction was performed with a 3-mL chloroform/methanol mixture (V/V). Phospholipids were isolated by thin layer chromatography on silica gel 60 plates (E Merck, Darmsmat, Germany) using petrol ether/diethylether/acetic acid $(80 \mathrm{~V} / 20 \mathrm{~V} / 1 \mathrm{~V})$ as the mobile phase. Fatty acid methyl esters were generated by transmethylation of the phospholipid fraction in 5\% acetyl chloride/95\% methanol and separated by gas chromatography. The fatty acid analysis was carried out with a Dani GC 1000 gas chromatograph equipped with a CP-Wax 58 capillary column, $50 \mathrm{~m}$ in length, $0.25 \mathrm{~mm}$ external diameter, $0.2 \mu \mathrm{m}$ thickness of the stationary phase (Varian Inc., Les Ulis, France), with helium $1 \mathrm{~mL} / \mathrm{min}$ as carrier gas and a programmed temperature $\left(60\right.$ to $\left.230^{\circ} \mathrm{C}\right)$. Programmed temperature vaporization injector and flame ionization detector were used. 1-2 dinonadecanoylsn 
glycerol-3 phosphatidyl choline (Interchim, Montluc, on, France) was used as internal standard.

\subsection{Oxidative stress measurement}

KRL test ("SPIRAL" laboratories, Couternon, France) is currently used to test the capability of erythrocytes to resist a standardized production of free radicals (http://www.nutriteck.com/sunyatakrl.html). The extracellular and intracellular antioxidant defenses contribute to maintain red blood cell membrane integrity and function until cell lysis. Blood samples were taken into evacuated tubes containing EDTA and kept at $4{ }^{\circ} \mathrm{C}$. Total blood or red blood cells separated from plasmas by centrifugation at $1730 \mathrm{~g}$ for $10 \mathrm{~min}$ at $4{ }^{\circ} \mathrm{C}$ were diluted to $1 / 50$ in isotonic saline solution and submitted to organic free radicals produced at $37^{\circ} \mathrm{C}$ under air atmosphere from the thermal decomposition of a $27 \mathrm{mmol} / \mathrm{L}$ solution of 2,2'-azobis (2-amidinopropane) dihydrochloride during 3 hours. Cell lysis was recorded using a 96-well microplate reader by measuring the optical density decay at $620 \mathrm{~nm}$. Half-lysis time (T1/2 in $\mathrm{min})$, the time at which $50 \%$ of cells have been lysed, is determined by calculating the time corresponding to OD1/2 according to the curve equation $\mathrm{OD}=\mathrm{f}(\mathrm{time})$ and the highest value of the curve (Vmax). Results are expressed as mean of T1/2 of erythrocytes (T1/2 erythro) and T1/2 of whole blood cells (T1/2 whole blood).

\subsection{Data analysis}

Numerical data were expressed as mean $\pm \mathrm{SD}$ (minimum-maximum). A descriptive analysis of the main patient's clinical and biological characteristics (displayed in Table 1) was performed using a principal component analysis with varimax rotation. Univariate analysis was performed with non-parametric 
tests, Mann-Whitney test and Spearman correlation test. Then factors independently associated with $\mathrm{T} 1 / 2$ erythro/T1/2 whole blood were identified using stepwise multiple linear regression models (entry threshold: F test pvalue $<0.1$ ). All these analyses were performed on 44 cases, i.e. one per patient. When more than one analysis was performed for one patient, we chose the first measure. Then, a second multivariate analysis was performed on all available measures using linear models fitted with the Generalized Estimating Equation method. We therefore analysed 72 cases, accounting for the nonindependence of measures among patients who had more than one oxidative stress evaluation. We used the SPSS 17.0 software (SPSS Inc., Chicago, IL, USA). All tests were two-sided and considered statistically significant at $\mathrm{p}<0.05$.

\section{Results}

\subsection{Description of the population}

In this study, 44 children ( 24 boys and 20 girls) were included. The mean age at the first KRL assessment was $12.2 \pm 3.8$ (5.9-19.1). Clinical characteristics of these children were reported on Table 1. Among these children, 5 (11.4\%) had a z-BMI lower than -2 ; the H/W ratio was lower than $85 \%$ in 7 children $(15.9 \%)$, between $85-90 \%$ in 3 children $(7 \%)$. None of these malnourished children was on enteral feeding at that time. Ninety-one percent of these patients were pancreatic insufficient. They were supplemented with vitamin A (43\%), vitamin E (91\%) and selenium (64\%) according to their respective blood values. Forty-three percent of patients were on ursodeoxycholic acid treatment. 
Their respiratory status was correct. The mean value of FEV1 was $94 \%$ (Table 1 ). Only 2 patients had a FEV1 $\leq 50 \%$. Congestion and exacerbation were reported respectively in $57 \%$ and $14 \%$ of the visits. Pseudomonas aeruginosa was found in $16 \%$ of the cultures performed in all of the visits. Only 2 patients did not have an antibiotic prophylaxis. At the time of evaluation, 15 patients (34\%), i.e 25 visits (35\%), were treated with itraconazole. In $38 \%$ of the visits, Brasfield score was $\geq 10$. Finally, in $86 \%$ of the visits, the patients had a good or excellent score of Shwachman $(\geq 70)$; none of them had a severe score.

The $\mathrm{C}$ reactive protein was available in 42 patients. Results were $<3$ $\mathrm{mg} / \mathrm{L}$, between $3-10 \mathrm{mg} / \mathrm{L}$, and $>10 \mathrm{mg} / \mathrm{L}$, respectively in $69 \%, 21 \%$, and $10 \%$ of the patients. Other biochemical results were reported in Table 2.

\subsection{Oxidative status}

The mean of $\mathrm{T} 1 / 2$ whole blood $(\mathrm{n}=72)$ was $90.3 \pm 11.4 \min (68.5-$ 121.7) (normal range: $85.15-102.60)$. The mean of $T 1 / 2$ erythro $(n=60)$ was $72.0 \pm 14.8$ min (24.9-125.0) (normal range: 65.35-81.78). As expected, the correlation between T1/2 whole blood and T1/2 erythro was statistically significant $(\rho=0.525, p=0.001)$.

\subsection{Principal component analysis}

The plane identified by the first two factorial axes, was found to explain $38 \%$ of the total inertia in the data (Figure 1). The variables that are close to one of the axes are correlated together. For example, the first factorial axis (factor 1) was mainly positively correlated to FEV1 and retinol/RBP, and mainly negatively correlated to orosomucoid, ceruloplasmin, triglycerides, and Brasfield score. The second factorial axis (factor 2) was mainly positively 
correlated to retinol, pre-albumin, and RBP. Inversely, the principal component analysis should suggest that age and GGT were not correlated to the other variables.

\subsection{Univariate analysis (Table 3)}

There is an association between sex and antioxidant potential. T1/2 whole blood and T1/2 erythro were significantly shorter in females than males, $92.2 \pm 12.4 v s .88 .4 \pm 10.2 \mathrm{~min}(\mathrm{p}=0.011)$, and $75.0 \pm 11.5$ vs. $68.9 \pm 17.2 \mathrm{~min}$ $(\mathrm{p}=0.052)$ respectively. There was no correlation of $\mathrm{T} 1 / 2$ whole blood or $\mathrm{T} 1 / 2$ erythro with age, and anthropometric parameters. We did not find any difference between $\mathrm{CF}$ patients who were treated or not with antioxidants (vitamin A, vitamin E, ursodeoxycholic acid (UDCA), or selenium). The amount of PERT was negatively correlated to T1/2 erythro $(\rho=-0.36, p=0.039)$. As it could be expected, the levels of selenium in the serum were positively correlated to $\mathrm{T} 1 / 2$ erythro $(\rho=0.35, \mathrm{p}=0.047)$ and $\mathrm{T} 1 / 2$ whole blood $(\rho=0.44$, $\mathrm{p}=0.004)$. Concerning PUFA of membrane phospholipids of erythrocytes, the $\omega 6 / \omega 3$ ratio was negatively correlated to $T 1 / 2$ erythro $(\rho=-0.37, p=0.030)$. However, there was no correlation with levels of PUFA (DHA, EPA, and AA), retinol, and $\alpha$-tocopherol.

Pulmonary functional tests revealed that only FEV1 was positively correlated to $\mathrm{T} 1 / 2$ erythro $(\rho=0.39, \mathrm{p}=0.018)$. Concerning the pulmonary infectious diseases of these patients, Pseudomonas aeruginosa colonisation was not correlated to antioxidant potential. However, patients that were on itraconazole treatment had lower antioxidant potential than patients that were not, statistically significant for T1/2 erythro, $65.7 \pm 12.6 \min v s .75 .8 \pm 14.9$ $\min (p=0.025)$. To note, these patients were not treated with itraconazole for 
acute broncho-pulmonory aspergillosis but for chronic colonisation. A shorter time of T1/2 erythro was found for acute exacerbation and congestion, $73.3 \pm$ $15.7 \min v s .65 .2 \pm 5.3 \min (\mathrm{p}=0.022)$ and $76.1 \pm 18.6 \min v s .68 .7 \pm 10.1 \mathrm{~min}$ $(\mathrm{p}=0.009)$. Finally, Brasfield score was negatively correlated to $\mathrm{T} 1 / 2$ eryhtro $(\rho=-0.48, \mathrm{p}=0.03)$ and $\mathrm{T} 1 / 2$ whole blood $(\rho=-0.32, \mathrm{p}=0.036)$.

We expected a negative correlation of antioxidant potential with inflammatory proteins. If there was a trend with C-reactive protein (CRP) and $\mathrm{T} 1 / 2$ erythro $(\mathrm{p}=0.063)$, we found a negative correlation of inflammatory proteins with $\mathrm{T} 1 / 2$ erythro: orosomucoid $(\rho=-0.62, \mathrm{p}<0.001)$ and ceruloplasmin $(\rho=-0.57, p<0.001)$. The number of blood leucocytes was negatively associated with $\mathrm{T} 1 / 2$ whole blood $(\rho=-0.36, \mathrm{p}=0.018)$ and $\mathrm{T} 1 / 2$ erythro $(\rho=-0.39, \mathrm{p}=0.025)$. 3.5. Multivariate analysis

For T1/2 erythro, 3 parameters were independently associated: Brasfield score, $\omega 6 / \omega 3$ ratio, and levels of selenium in the serum. However, this latter parameter could be excluded when we analysed all the results of KRL test performed for the same patient. Finally, Brasfield score and $\omega 6 / \omega 3$ ratio remained independently negatively correlated to $\mathrm{T} 1 / 2$ erythro, $\beta=-0.611$ $(\mathrm{p}<0.001)$ and $\beta=-1.213(\mathrm{p}=0.013)$ respectively.

For T1/2 whole blood, 2 parameters were independently associated: sex and MMEF. After accounting for all the available measures, only the sex remained significantly correlated to $\mathrm{T} 1 / 2$ whole blood $(\mathrm{p}=0.015)$. 


\section{Discussion:}

The KRL test represents the capability of a person to react to an oxidative stress. In our study, T1/2 erythro was significantly associated with a decrease of plasma level of selenium. The decrease of this antioxidant could alter the selenium-dependant GSH peroxidase, as it was reported [1]. T1/2 erythro was also associated with pulmonary congestion and exacerbation, i.e. may be with an increase of ROS in the lungs. To our knowledge, the correlation of oxidative stress and Brasfield score was not previously described. In our study, this score was the only respiratory parameter that remained statistically significant in multivariate analysis. More than air trapping, this association could be due to bronchiectasis. In the literature, oxidative stress was present during acute respiratory exacerbations and it improved after treatment of exacerbation [18]. The oxidation of proteins that were present in bronchoalveolar lavage fluids was negatively correlated to FEV1 values [19]. However, oxidative stress remains present in stable CF patients and it could also contribute to chronic pulmonary inflammation [5]. Similarly, a recent study assessed plasma and cellular oxidative stress biomarkers in stable adults with bronchiectasis ( $36 \mathrm{CF}$, and 54 without $\mathrm{CF}$ ), and in 50 healthy controls [20]. Oxidative stress biomarkers were increased in patients with bronchiectasis compared with controls, without difference between CF and not CF patients.

The relation of good nutritional status and pulmonary function is well established [21]. We did not find any association between antioxidant capability, assessed by the KRL test, and anthropometric parameters. However, the fact that the amount of PERT was associated in univariate analysis with 
T1/2 erythro should suggest that pancreatic insufficiency by itself rather than clinical nutritional status is involved in oxidative stress in CF. Lezo et al. recently reported that $\mathrm{CF}$ patients with pancreatic insufficiency had higher levels of lipid peroxidation biomarkers than patients with pancreatic sufficiency [5]. We did not find any significant differences between oxidative stress and fat-soluble vitamins. The antioxidant capabilities of patients that were not treated with antioxidant vitamins were similar to those of supplemented patients. Abnormalities of fatty acids that occurs in CF seems to be of importance $[7,10]$. In multivariate analysis, we found a significant negative correlation of $\omega 6 / \omega 3$ ratio and T1/2 erythro. The increase of $\omega 6 / \omega 3$ ratio is associated with a decrease of antioxidant potential of CF patients, with synthesis of pro-inflammatory lipid mediators and reduction of resolvins, involved in the resolution of inflammation [12]. A limitation of our study is that we did not test these lipid mediators, but they were not routinely available. In further studies, we should assess plasma levels of protaglandins (PGE2), leucotriens (LTB4), and eicosanoids (5-HETE) that are the products of the oxidation of AA by cyclooxygenase and 5-lipoxygenase. They could be of better interest than AA, EPA, and DHA levels that were not associated with oxidative stress in our study. However, ratio of $\omega 6 / \omega 3$ or AA/DHA could be of greater importance than the quantity of fatty acids $[7,10]$.

In order to effectively manage oxidative stress in $\mathrm{CF}$, we could hypothesize that: (i) plasma antioxidant normal values are too low in the setting of CF; (ii) antioxidant levels within the airway are more important than the plasma levels; (iii) trials are needed to determine appropriate antioxidant regimen $[5,6]$. New formulations of fat-soluble vitamins and antioxidants have 
been tested since few years $[22,23]$. The formulation increased plasma levels of $\beta$-carotene, $\gamma$-tocopherol and CoQ-10. Improvement of their antioxidant score was correlated to a decreased airway inflammation assessed by levels of IL-8 and total neutrophils in sputum. This score combined the values of these levels of several antioxidants pre and post-treatment. However, this score was complex and only determined in 10 patients. Moreover, pre and post-levels of IL-8 and especially total neutrophils only decreased in few patients [22]. The formulation is now commercialised as AquADEKs $\AA$, a formulation containing several fat-soluble vitamins, water-soluble vitamins, micronutrients, and antioxidants. An open-label non-randomised study enrolled $14 \mathrm{CF}$ patients [23]. The authors only found an improvement of plasma levels of some antioxidants ( $\beta$-carotene, CoQ-10, and $\gamma$-tocopherol). No correlation was found with urine 8-isoprostane levels. In recent reviews, details on antioxidant trials in CF were summarized $[1,6]$. Our data suggest that the KRL test is an interesting tool to assess antioxidant potential in CF. Moreover, its correlation with pulmonary status could dispense of the measure of BAL oxidative biomarkers that are more invasive. This test could allow to follow the antioxidant potential of $\mathrm{CF}$ children and to monitor the effectiveness of antioxidant intervention.

In conclusion, the present study demonstrated that the whole antioxidant capability, measured by the KRL test, should be a useful biomarker to assess oxidative stress in $\mathrm{CF}$ patients. It was associated with pulmonary status. The better respiratory parameter correlated to antioxidant potential was Brasfield score. The efficiency of the KRL test was greater in erythrocytes than in whole blood cells. This study should suggest that $\omega 6 / \omega 3$ ratio could be more relevant than fat-soluble antioxidant vitamin levels to assess oxidative stress in 
CF. Finally, an interventional trial is required to evaluate the usefulness of this test to detect post-treatment improvements.

\section{Acknowledgements:}

Emmanuel Mas was the recipient of a grant from Lactalis under the aegis of the Groupe Francophone d'Hépatologie, Gastroentérologie et Nutrition Pédiatrique. The funders had no role in study design, data collection and analysis, decision to publish, or preparation of the manuscript. 


\section{References:}

1. Galli, F., Battistoni, A., Gambari, R., Pompella, A., Bragonzi, A., Pilolli, F., Iuliano, L., Piroddi, M., Dechecchi, M. C., and Cabrini, G. (2012) Oxidative stress and antioxidant therapy in cystic fibrosis. Biochim. Biophys. Acta. 1822, 690-713.

2. Lezo, A., Biasi, F., Massarenti, P., Calabrese, R., Poli, G., Santini, B., and Bignamini, E. (2013) Oxidative stress in stable cystic fibrosis patients: do we need higher antioxidant plasma levels? J. Cyst. Fibros. 12, 35-41.

3. Cantin, A. M., White, T. B., Cross, C. E., Forman, H. J., Sokol, R. J., and Borowitz, D. (2007) Antioxidants in cystic fibrosis. Conclusions from the CF antioxidant workshop, Bethesda, Maryland, November 11-12, 2003. Free Radic. Biol. Med. 42, 15-31.

4. Dodge, J. A., and Turck, D. (2006) Cystic fibrosis: nutritional consequences and management, Best. Pract. Res. Clin. Gastroenterol. 20, 531-546.

5. Borowitz, D., Baker, R. D., and Stallings, V. (2002) Consensus report on nutrition for pediatric patients with cystic fibrosis. J. Pediatr. Gastroenterol. Nutr. 35, 246-259.

6. Miller, E. R., 3rd, Pastor-Barriuso, R., Dalal, D., Riemersma, R. A., Appel, L. J., and Guallar, E. (2005) Meta-analysis: high-dosage vitamin E supplementation may increase all-cause mortality. Ann. Intern. Med. $142,37-46$.

7. Omenn, G. S. (2007) Chemoprevention of lung cancers: lessons from CARET, the beta-carotene and retinol efficacy trial, and prospects for the future. Eur. J. Cancer Prev. 16, 184-191. 
8. Zapletal, A., Motoyama, E. K., Van De Woestijne, K. P., Hunt, V. R., and Bouhuys, A. (1969) Maximum expiratory flow-volume curves and airway conductance in children and adolescents. J. Appl. Physiol. 26, Mis en forme : Anglais (États-Unis) 308-316.

9. Caspar-Bauguil, S., Maestre, N., Segafredo, C., Galinier, A., Garcia, J., Prost, M., Periquet, B., Penicaud, L., Salvayre, R., and Casteilla, L. (2009) Evaluation of whole antioxidant defenses of human mononuclear cells by a new in vitro biological test: lack of correlation between erythrocyte and mononuclear cell resistance to oxidative stress. Clin. Biochem. 42, 510-514.

10. Range, S. P., Dunster, C., Knox, A. J., and Kelly, F. J. (1999) Treatment of pulmonary exacerbations of cystic fibrosis leads to improved antioxidant status. Eur. Respir. J. 13, 560-564.

11. Starosta, V., Rietschel, E., Paul, K., Baumann, U., and Griese, M. (2006) Oxidative changes of bronchoalveolar proteins in cystic fibrosis. Chest. $129,431-437$.

12. Olveira, G., Olveira, C., Dorado, A., Garcia-Fuentes, E., Rubio, E., Tinahones, F., Soriguer, F., and Murri, M. (2013) Cellular and plasma oxidative stress biomarkers are raised in adults with bronchiectasis. Clin. Nutr. 32, 112-117.

13. Munck, A. (2010) Nutritional considerations in patients with cystic fibrosis. Expert Rev. Respir. Med. 4, 47-56.

14. Papas, K. A., Sontag, M. K., Pardee, C., Sokol, R. J., Sagel, S. D., Accurso, F. J., and Wagener, J. S. (2008) A pilot study on the safety and efficacy 
of a novel antioxidant rich formulation in patients with cystic fibrosis. $J$. Cyst. Fibros. 7, 60-67.

15. Sagel, S. D., Sontag, M. K., Anthony, M. M., Emmett, P., and Papas, K. A. (2011) Effect of an antioxidant-rich multivitamin supplement in cystic fibrosis. J. Cyst. Fibros. 10, 31-36. 
Figure 1. Principal Component Analysis, plane of the first two components

(Factor 1 and Factor 2). To note, this two factorial axes explained 38\% of the total inertia in the data. The variables that are close to one of the axes are correlated together.

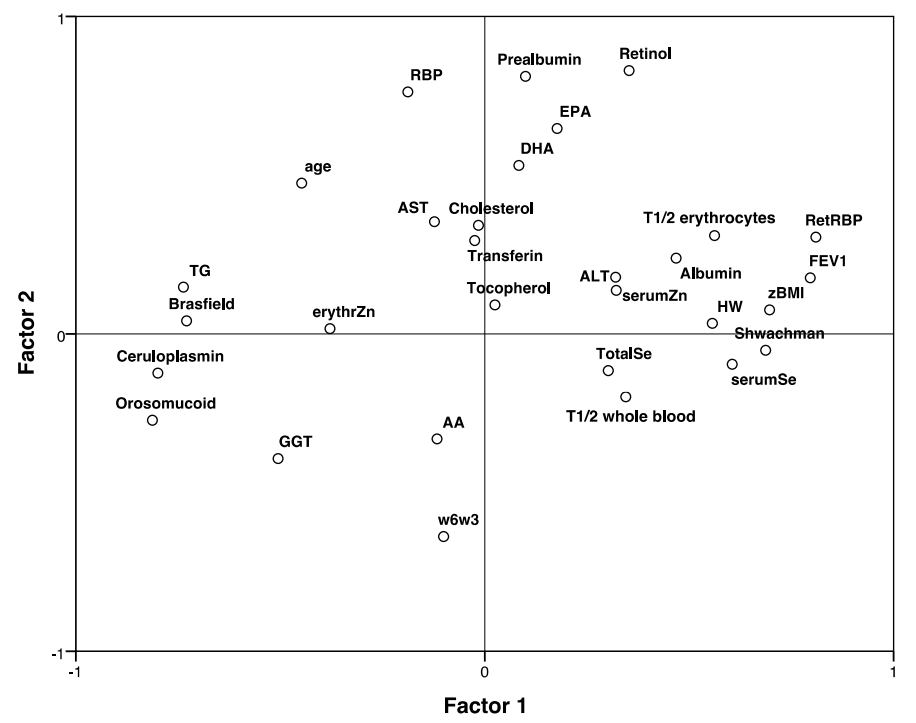

AA: arachidonic acid, ALT: alanine amino-transferase, AST: aspartate aminotransferase, DHA: docosahexaenoic acid, EPA: eicosapentaenoic acid, erythrZn: erythrocyte Zinc, FEV1: forced expiratory volume in 1 second, GGT: gamma-glutamyl transpeptidase, HW: height to weight ratio, TG: triglycerides, TotalSe: whole blood Selenium, w6w3: $\omega 6 / \omega 3$ ratio, zBMI: zscore of body mass index, 
Table 1: Clinical characteristics of CF children

\begin{tabular}{|c|c|c|c|c|c|}
\hline & $\mathbf{N}$ & mean & SD & Min & Max \\
\hline Age (year) & 44 & 12.2 & 3.8 & 5.9 & 19.1 \\
\hline z-BMI & 44 & -0.5 & 1.2 & -3.8 & 2.7 \\
\hline $\mathrm{H} / \mathrm{W}$ ratio & 44 & 96 & 11 & 68 & 122 \\
\hline FEV1 (\%) & 44 & 94 & 22 & 33 & 142 \\
\hline Brasfield score & 44 & 7.5 & 3.3 & 1 & 14 \\
\hline Shwachman score & 44 & 82 & 9 & 60 & 100 \\
\hline $\begin{array}{l}\text { PERT } \\
\text { (U lipase/kg/d) }\end{array}$ & 40 & 4501 & 1478 & 2455 & 8471 \\
\hline Sputum & & \multicolumn{2}{|c|}{ positive } & \multicolumn{2}{|c|}{ negative } \\
\hline \multicolumn{2}{|l|}{ Staphylococcus aureus } & \multicolumn{2}{|c|}{54} & \multicolumn{2}{|c|}{18} \\
\hline \multicolumn{2}{|l|}{ Pseudomonas aeruginosa } & \multicolumn{2}{|c|}{13} & \multicolumn{2}{|c|}{59} \\
\hline \multirow[t]{6}{*}{ Genotypes } & $\mathbf{N}$ & \multicolumn{2}{|c|}{ Mutation 1} & \multicolumn{2}{|c|}{ Mutation 2} \\
\hline & 4 & \multicolumn{2}{|c|}{$\begin{array}{l}\text { c.1521_1523delCTT } \\
\text { (p.Phe508del) }\end{array}$} & \multicolumn{2}{|c|}{$\begin{array}{l}\text { c.1624G>T } \\
\text { (p.Gly542X) }\end{array}$} \\
\hline & 2 & \multicolumn{2}{|c|}{$\begin{array}{l}\text { c.1521_1523delCTT } \\
\text { (p.Phe508del) }\end{array}$} & \multicolumn{2}{|c|}{$\begin{array}{c}\text { c.3605delA } \\
\text { (P.Asp120AlafsX9) }\end{array}$} \\
\hline & 2 & \multicolumn{2}{|c|}{$\begin{array}{l}\text { c.1521_1523delCTT } \\
\text { (p.Phe508del) }\end{array}$} & \multicolumn{2}{|c|}{$\begin{array}{c}\text { c.617T >G } \\
\text { (p.Leu206Trp) }\end{array}$} \\
\hline & 8 & \multicolumn{2}{|c|}{$\begin{array}{l}\text { c.1521_1523delCTT } \\
\text { (p.Phe508del) }\end{array}$} & \multicolumn{2}{|c|}{ other mutation } \\
\hline & 4 & \multicolumn{2}{|c|}{ other mutation } & \multicolumn{2}{|c|}{ other mutation } \\
\hline
\end{tabular}

FEV1: forced expiratory volume in 1 second, H/W ratio: height to weight ratio, PERT: pancreatic enzyme replacement therapy, z-BMI: z-score of body mass index. 


\section{Table 2: Biochemical characteristics of CF children}

\begin{tabular}{|c|c|c|c|c|c|}
\hline & $\mathbf{N}$ & mean & SD & Min & Max \\
\hline AST (ULN) & 40 & 0.7 & 0.2 & 0.3 & 1.6 \\
\hline ALT (ULN) & 40 & 0.6 & 0.4 & 0.2 & 2.0 \\
\hline GGT (ULN) & 40 & 0.5 & 0.3 & 0.2 & 2.0 \\
\hline $\operatorname{Albumin}(g / L)$ & 42 & 39.4 & 4.1 & 31.0 & 49.9 \\
\hline Pre-albumin $(g / L)$ & 42 & 0.20 & 0.05 & 0.11 & 0.31 \\
\hline Orosomucoid (g/L) & 42 & 0.92 & 0.37 & 0.40 & 2.50 \\
\hline Ceruloplasmin $(\mathrm{g} / \mathrm{L})$ & 42 & 0.39 & 0.15 & 0.20 & 0.90 \\
\hline Transferrin (g/L) & 42 & 2.9 & 0.4 & 2.1 & 3.9 \\
\hline Retinol binding protein $(\mathrm{g} / \mathrm{L})$ & 42 & 0.033 & 0.010 & 0.013 & 0.062 \\
\hline Whole blood selenium & 38 & & & & \\
\hline$(\mu \mathrm{mol} / \mathrm{L})$ & & 0.97 & 0.20 & 0.63 & 1.45 \\
\hline Serum selenium $(\mu \mathrm{mol} / \mathrm{L})$ & 41 & 0.86 & 0.19 & 0.53 & 1.39 \\
\hline Serum zinc $(\mu \mathrm{mol} / \mathrm{L})$ & 42 & 12.9 & 2.0 & 8.5 & 17.0 \\
\hline Erythrocyte zinc ( $\mu \mathrm{mol} / \mathrm{L})$ & 42 & 165 & 31 & 95 & 220 \\
\hline Retinol (mg/L) & 42 & 0.38 & 0.12 & 0.15 & 0.68 \\
\hline Retinol/RBP & 42 & 0.85 & 0.08 & 0.67 & 1.06 \\
\hline$\alpha$-tocopherol (mg/L) & 42 & 8.5 & 2.2 & 4.8 & 13.6 \\
\hline Total cholesterol $(\mathrm{mmol} / \mathrm{L})$ & 41 & 3.14 & 0.64 & 1.70 & 4.90 \\
\hline Triglycerides (mmol/L) & 41 & 0.83 & 0.37 & 0.38 & 1.90 \\
\hline EPA $(\mathbf{m g} / \mathbf{L})$ & 42 & 10.5 & 4.2 & 3.5 & 22.8 \\
\hline DHA (mg/L) & 42 & 67.2 & 18.4 & 33.8 & 115.6 \\
\hline $\mathbf{A A}(\mathbf{m g} / \mathbf{L})$ & 42 & 257.9 & 28.9 & 199.0 & 328.0 \\
\hline$\omega 6 / \omega 3$ & 42 & 4.7 & 1.1 & 2.8 & 8.6 \\
\hline
\end{tabular}


AA: arachidonic acid, ALT: alanine amino-transferase, AST: aspartate aminotransferase, DHA: docosahexaenoic acid, EPA: eicosapentaenoic acid, GGT: gamma-glutamyl transpeptidase, ULN: upper limit of normal. 


\section{Table 3: Univariate analysis of continuous variables (Spearman}

$\underline{\text { correlation test) }}$

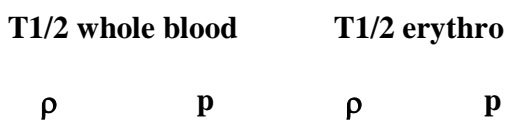

Anthropometric parameters

$\begin{array}{lllll}\text { Age } & -0.067 & 0.665 & -0.206 & 0.229 \\ \text { Weight } & 0.012 & 0.940 & -0.096 & 0.579 \\ \text { Height } & -0.040 & 0.797 & -0.112 & 0.517 \\ \text { H/W } & 0.193 & 0.209 & 0.107 & 0.533\end{array}$

Pulmonary functional tests and severity scores

$\begin{array}{lcccc}\text { FEV1 } & 0.122 & 0.428 & 0.392 & 0.018 \\ \text { MMEF } & 0.279 & 0.066 & 0.329 & 0.050 \\ \text { Brasfield score } & -0.317 & 0.036 & -0.475 & 0.003 \\ \text { Shwachman score } & 0.168 & 0.276 & 0.321 & 0.056 \\ \text { Treatment } & & & & \\ \text { UDCA (mg/kg/d) } & 0.134 & 0.387 & 0.234 & 0.169 \\ \text { PERT (U lipase/kg/d) } & -0.125 & 0.443 & -0.361 & 0.039 \\ \text { Biological parameters } & & & & \\ \text { Leucocytes } & & & & \\ \text { Serum Se } & -0.363 & 0.018 & -0.385 & 0.025 \\ \text { Total Se } & 0.435 & 0.004 & 0.349 & 0.047 \\ \text { Serum Cu } & 0.278 & 0.091 & 0.058 & 0.759 \\ \text { Retinol } & -0.153 & 0.340 & -0.354 & 0.043 \\ \text { a-tocopherol } & 0.050 & 0.752 & 0.241 & 0.170 \\ \text { Orosomucoid } & 0.116 & 0.465 & -0.041 & 0.819 \\ & -0.236 & 0.132 & -0.617 & <0.001 \\ & & & & \end{array}$




$\begin{array}{lllll}\text { Ceruloplasmin } & -0.232 & 0.140 & -0.568 & <0.001 \\ \text { DHA } & 0.200 & 0.203 & 0.232 & 0.187 \\ \text { EPA } & 0.188 & 0.233 & 0.280 & 0.108 \\ \text { AA } & -0.126 & 0.428 & -0.130 & 0.465 \\ \mathbf{\omega 6} / \omega 3 & -0.266 & 0.088 & -0.372 & 0.030\end{array}$

AA: arachidonic acid, $\mathrm{Cu}$ : cupper, DHA: docosahexaenoic acid, EPA: eicosapentaenoic acid, FEV1: forced expiratory volume in 1 second, H/W: height to weight ratio, MMEF: maximum midexpiratory flow, PERT: pancreatic enzyme replacement therapy, Se: selenium, T1/2 erythro : half-lysis time of erythrocytes, T1/2 whole blood : half-lysis time of whole blood cells, UDCA: ursodeoxycholic acid. 


\section{Corresponding author:}

Emmanuel Mas, MD, PhD

Unité de Gastroentérologie, Hépatologie et Nutrition

330, avenue de Grande-Bretagne - TSA 70034

31059 Toulouse cedex 9

France

Tel. (33) 534558445

Fax. (33) 534558567

E-mail: $\underline{\text { mas.e@ @ chu-toulouse.fr }}$

1. Galli, F., et al., Oxidative stress and antioxidant therapy in cystic fibrosis. Biochim Biophys Acta, 2012. 1822(5): p. 690-713.

2. Brown, R.K. and F.J. Kelly, Evidence for increased oxidative damage in patients with cystic fibrosis. Pediatr Res, 1994. 36(4): p. 487-93.

3. Wood, L.G., et al., Improved antioxidant and fatty acid status of patients with cystic fibrosis after antioxidant supplementation is linked to improved lung function. Am J Clin Nutr, 2003. 77(1): p. 150-9.

4. van der Vliet, A., et al., Oxidative stress in cystic fibrosis: does it occur and does it matter? Adv Pharmacol, 1997. 38: p. 491-513.

5. Lezo, A., et al., Oxidative stress in stable cystic fibrosis patients: do we need higher antioxidant plasma levels? J Cyst Fibros, 2013. 12(1): p. 35-41.

6. Cantin, A.M., et al., Antioxidants in cystic fibrosis. Conclusions from the CF antioxidant workshop, Bethesda, Maryland, November 11-12, 2003. Free Radic Biol Med, 2007. 42(1): p. 15-31.

7. Iuliano, L., et al., Association of cholesterol oxidation and abnormalities in fatty acid metabolism in cystic fibrosis. Am J Clin Nutr, 2009. 90(3): p. 477-84.

8. Wood, L.G., et al., Increased plasma fatty acid concentrations after respiratory exacerbations are associated with elevated oxidative stress in cystic fibrosis patients. Am J Clin Nutr, 2002. 75(4): p. 668-75.

9. Dodge, J.A. and D. Turck, Cystic fibrosis: nutritional consequences and management. Best Pract Res Clin Gastroenterol, 2006. 20(3): p. 531-46.

10. Freedman, S.D., et al., Association of cystic fibrosis with abnormalities in fatty acid metabolism. N Engl J Med, 2004. 350(6): p. 560-9.

11. Roulet, M., et al., Essential fatty acid deficiency in well nourished young cystic fibrosis patients. Eur J Pediatr, 1997. 156(12): p. 952-6. 
12. Serhan, C.N., et al., Resolvins, docosatrienes, and neuroprotectins, novel omega-3-derived mediators, and their endogenous aspirintriggered epimers. Lipids, 2004. 39(11): p. 1125-32.

13. Borowitz, D., R.D. Baker, and V. Stallings, Consensus report on nutrition for pediatric patients with cystic fibrosis. J Pediatr Gastroenterol Nutr, 2002. 35(3): p. 246-59.

14. Miller, E.R., 3rd, et al., Meta-analysis: high-dosage vitamin E supplementation may increase all-cause mortality. Ann Intern Med, 2005. 142(1): p. 37-46.

15. Omenn, G.S., Chemoprevention of lung cancers: lessons from CARET, the beta-carotene and retinol efficacy trial, and prospects for the future. Eur J Cancer Prev, 2007. 16(3): p. 184-91.

16. Zapletal, A., et al., Maximum expiratory flow-volume curves and airway conductance in children and adolescents. J Appl Physiol, 1969. 26(3): p. 308-16.

17. Caspar-Bauguil, S., et al., Evaluation of whole antioxidant defenses of human mononuclear cells by a new in vitro biological test: lack of correlation between erythrocyte and mononuclear cell resistance to oxidative stress. Clin Biochem, 2009. 42(6): p. 510-4.

18. Range, S.P., et al., Treatment of pulmonary exacerbations of cystic fibrosis leads to improved antioxidant status. Eur Respir J, 1999. 13(3): p. 560-4.

19. Starosta, V., et al., Oxidative changes of bronchoalveolar proteins in cystic fibrosis. Chest, 2006. 129(2): p. 431-7.

20. Olveira, G., et al., Cellular and plasma oxidative stress biomarkers are raised in adults with bronchiectasis. Clin Nutr, 2013. 32(1): p. 112-7.

21. Munck, A., Nutritional considerations in patients with cystic fibrosis. Expert Rev Respir Med, 2010. 4(1): p. 47-56.

22. Papas, K.A., et al., A pilot study on the safety and efficacy of a novel antioxidant rich formulation in patients with cystic fibrosis. J Cyst Fibros, 2008. 7(1): p. 60-7.

23. Sagel, S.D., et al., Effect of an antioxidant-rich multivitamin supplement in cystic fibrosis. J Cyst Fibros, 2011. 10(1): p. 31-6. 